\title{
Kajian Sanitasi Sekolah Dasar Di Kabupaten Kayong Utara Provinsi Kalimantan Barat
}

\author{
Reza Wahyudi ${ }^{1{ }^{1 *},}$ Nia Febrianti², Murti Juliandari ${ }^{3}$ \\ ${ }^{1,3}$ Program Studi Teknik Lingkungan, Universitas Nahdlatul Ulama Kalimantan Barat, Pontianak, 78111. \\ ${ }^{2}$ Program Studi Teknik Lingkungan Institut Teknologi Kalimantan, Balikpapan, 76111. \\ *Koresponden Email: rezawahyudihse49@gmail.com
}

Diterima : 19 Juni 2019

Disetujui: 3 Juli 2019

\begin{abstract}
The sanitation study of the Primary School in Kayong Utara District demands that the Sanitation Risk Area be established in the EHRA study. Based on the EHRA study, the classification of risk categories is divided into three which are namely No, Medium, and Very High Risk. The scope of the study area covers the elementary schools and this encompasses 18 high-risk villages from 4 sub-districts. And the total number of primary and secondary schools in the study conducted was thirty-three. This study used a questionnaire method that was provided by the school for self-assessment. The result stated that sanitation was in an unpleasant category and it can be broken down to the provision of handwashing (35.52\%), trash temporary shelter (45.44\%), drainage channel (43.42) and PHBS education and practice (47.32\%).
\end{abstract}

Keywords: Sanitation, Study EHRA, PHBS, Asesmen Mandiri, Kayong Utara

\begin{abstract}
Abstrak
Kajian sanitasi Sekolah Dasar di Kabupaten Kayong Utara mengacu pada Area Berisiko Sanitasi yang telah ditetapkan pada studi EHRA. Berdasarkan studi EHRA pengklasifikasian kategori resiko dibagi menjadi 3 yaitu Tidak Berisiko, Resiko Sedang dan Resiko Sangat Tinggi. Ruang lingkup wilayah kajian yaitu sekolah dasar yang termasuk dalam desa berisiko sanitasi sangat tinggi. Adapun dalam studi. Penentuan Desa yang memiliki resiko sanitasi yang sangat tinggi berjumlah 18 Desa dari 4 Kecamatan dan total Sekolah Dasar yang dilakukan pengambilan data primer dan sekunder sebanyak 33 Sekolah Dasar. Kajian ini juga mengunakan metode kuisioner yang disi oleh pihak sekolah atau self-assesment. Hasil Self Assesment tersebut menyatakan bahwa kondisi sanitasi dengan kategori buruk yaitu fasilitas cuci tangan (35,52\%), tempat penampungan sementara (TPS) sampah $(45,44 \%)$, saluran drainase $(43,42)$ dan pendidikan dan praktek PHBS $(47,32 \%)$.
\end{abstract}

Kata Kunci: Sanitasi, Studi EHRA, PHBS, Self Assesment, Kayong Utara

\section{Pendahuluan}

Sanitasi di sekolah merupakan hal yang penting diterapkan saat ini. Siswa tidak hanya diajarkan di dalam kelas tentang sanitasi, namun siswa diharapkan dapat mempraktekan teori yang telah mereka pelajari di dalam kelas. Oleh karena itu diperlukan fasilitas sanitasi yang memadai di lingkungan sekolah. Berdasarkan hasil profil sanitasi sekolah 2017 bahwa $12,09 \%$ atau 25.835 sekolah tidak memiliki jamban, $35,19 \%$ atau 75.193 sekolah tidak memiliki fasilitas cuci tangan (Ana, G, dkk., 2008). Hal tersebut menjadi permasalahan yang penting untuk segera diselesaikan. Sanitasi sekolah merupakan langkah awal untuk mewujudkan lingkungan belajar yang sehat.

Namun tidak semua sekolah memperhatikan sanitasi sekolah, padahal sanitasi sekolah dapat berpengaruh terhadap kualitas pendidikan dan produktifitas belajar siswa. Akses air dasar dan sanitasi merupakan prasyarat untuk hak atas pendidikan dasar untuk anak sekolah (Adams, J, dkk., 2009). Perilaku Hidup Bersih dan Sehat (PHBS) yang tidak diterapkan oleh sekolah dapat menimbulkan penyakit bagi siswa antara lain penyebaran penyakit diare dan demam berdarah. Permasalahan yang sering muncul terkait dengan sanitasi sekolah ini seperti sekolah memiliki jamban namun tidak terpelihara dengan baik atau jamban tersebut keterbatasan air sehingga tidak maksimal dalam penggunaannya dan cenderung menimbulkan penyakit. Hal sederhana dapat dilihat pada kegiatan cuci tangan dengan sabun yang dapat menurunkan resiko diare hingga 47\% (Profil Sanitasi, 2007). Demi mengembangkan peserta didik yang sehat, sekolah perlu menjaga kesehatan lingkungan sekolah. Seperti yang diungkapkan oleh Dina Andriati, 


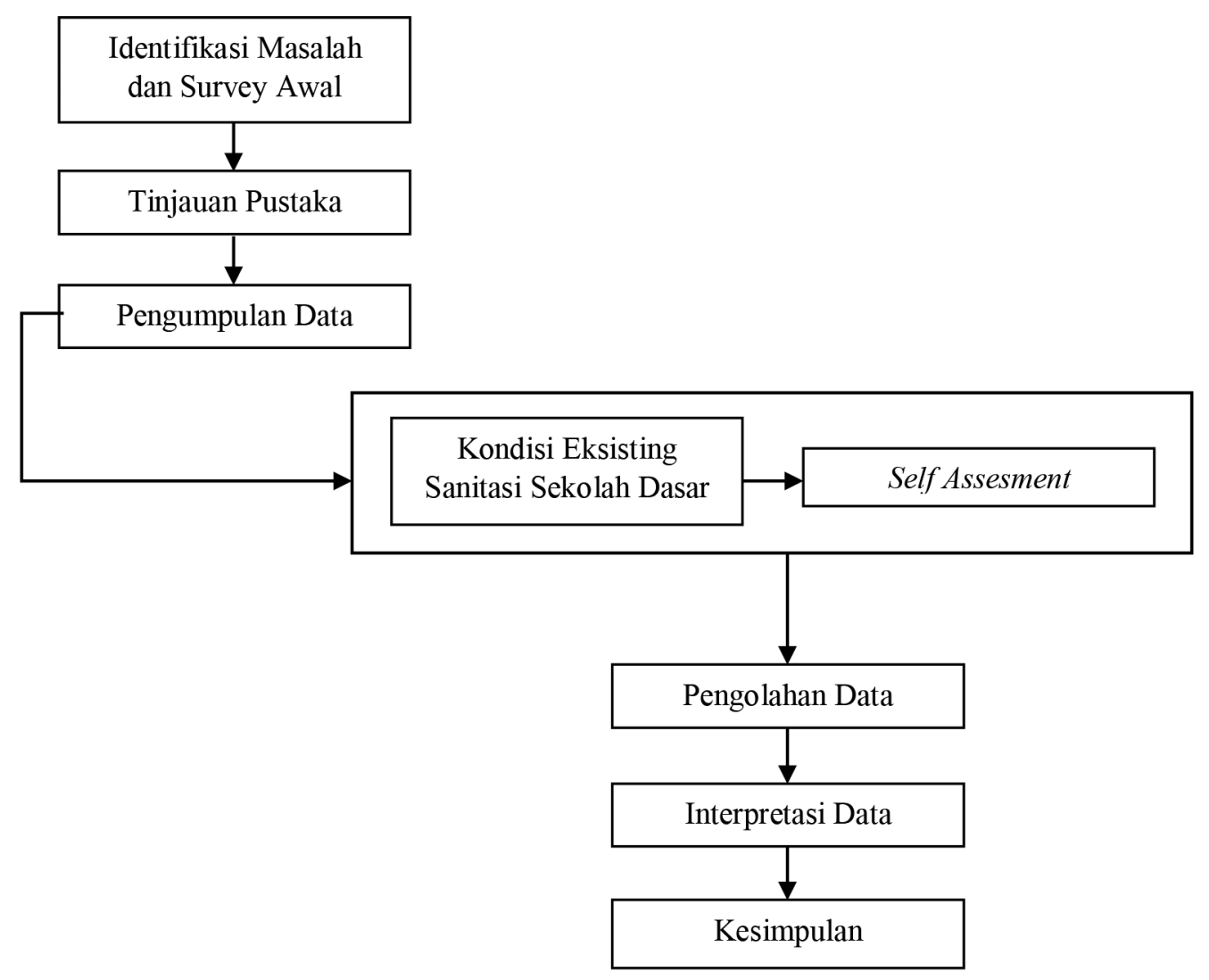

Gambar 1. Bagan Alir Penelitian

dkk. (2013:2) bahwa lingkungan sekolah yang sehat akan mendukung tumbuh kembang perilaku hidup sehat serta berdampak bagi kesehatan jasmani maupun rohani dan terhindar dari pengaruh negatif yang dapat merusak kesehatan.

Siswa yang sehat dan terhindar dari penyakit yang diakibatkan lingkungan yang kotor seperti diare dapat meningkatkan produktifitas siswa. Misalnya pembiasaan Cuci Tangan Pakai Sabun (CTPS) secara rutin dapat menurunkan angka ketidakhadiran secara signifikan yaitu mencapai 50\% (Mooijman, A, 2012). Di dalam Peraturan Menteri Kesehatan Nomor 3 tahun 2014 tentang STBM menjelaskan bahwa cuci tangan pakai sabun adalah perilaku cuci tangan dengan menggunakan air bersih yang mengalir dan sabun. Penyakit diare yang paling besar berkontribusi pada tingkat kematian sekitar 1,9 juta dan kasus diare tersebut diperkirakan mencapai 4 miliar setiap tahun terutama dikalangan anak di bawah lima tahun. Negaranegara berkembang berkontribusi menyumbang sekitar 19\% dari tingkat kematian (Freeman, dkk., 2014). Di sekolah, pendidikan kebersihan dan sanitasi bertujuan untuk mempromosikan praktik-praktik yang akan membantu siswa mencegah penyakit terkait sanitasi serta untuk mempromosikan perilaku sehat pada generasi orang dewasa di masa depan (O'Reily dkk., 2006).

Berdasarkan hasil statistik profil sanitasi sekolah dasar 2017 di Kalimantan Barat. Akses air tidak layak ataupun tidak memiliki akses air dasar yaitu 56,93\%, jamban tidak layak atau tidak memiliki jamban $14,74 \%$, tidak ada sarana fasilitas cuci tangan 50,20\%. Kondisi sanitasi yang sangat memperhatinkan tersebut secara langsung berhubungan dengan kualitas dan produktifitas siswa di sekolah dasar. Kebijakan yang positif diperlukan pada setiap tingkatan mulai kebijakan nasional, kabupaten, lokal dan sekolah. Hal tersebut dilakukan untuk mendorong dan memfasilitasi pencapaian tingkat air, sanitasi dan kebersihan di sekolah (Burgers, L, 2000).

Berdasarkan Permendiknas Nomor 24 Tahun 2007 tentang standar sarana dan prasarana untuk sekolah dasar menyatakan bahwa sebuah sekolah dasar sekuarang-kurangnya memiliki prasarana yaitu ruang kelas, ruang perpustakaan, laboratorium IPA, ruang pimpinan, ruang guru, tempat ibadah, ruang UKS, jamban, gudang, ruang sirkulasi, dan tempat olahraga.

Berdasarkan hasil studi EHRA tahun 2018 masyarakat Kabupaten Kayong Utara dalam mengelola sarana sumber air bersih untuk memenuhi 
kebutuhan air minum, masak, cuci piring, cuci pakai dan gosok gigi, yang berisiko tercemar sebesar 95,3\%, disamping itu masyarakat mengakses air dari sumber air yang tidak terlindung dan tidak aman akan terjadinya pencemaran sebesar 88,8\% dan pernah mengalami kesulitan mendapatkan air untuk kebutuhan sehari-hari sebesar 40,7\%. Hal ini menunjukan ada risiko kesehatan atau dampak yang tidak baik terhadap kesehatan anggota rumah tangga karena faktor sumber air bersih. Secara total rumah responden yang mempunyai jamban pribadi dengan persentase sebesar 80,6\%, dan anggota keluarga yang sudah dewasa bila ingin buang air besar menggunakan MCK Umum sebesar 1,7 \%, dan juga ada beberapa responden dan atau anggota keluarganya yang masih belum atau tidak menggunakan jamban pada waktu buang air besar yaitu sebesar 1,2\% membuang air besar langsung ke sungai/ pantai/ laut, di kebun/ pekarangan sebesar 11,4\%. Komponen pengelolaan sampah secara total, responden pada seluruh Kluster dalam mengelola sampah rumah tangga tersebut dengan jumlah sebesar 79,7 \% dengan cara dibakar, selanjutnya masyarakat yang membuang sampah yang dibuang ke lahan kosong/kebun/hutan dan dibiarkan membusuk sebesar 8,2\%, Sampah dibiarkan saja sampai membusuk sebesar 5,5\%, dibuang ke dalam lubang tetapi tidak ditutup dengan tanah sebesar 3,7\%, dan dibuang kesungai/ kali/ laut/ danau sebesar 1,7\%.

Penelitian ini bertujuan untuk mengetahui kondisi sanitasi sekolah dasar secara terperinci sehingga dapat menjadi bahan pertimbangan dinas terkait untuk meningkatkan kualitas sanitasi di sekolah dasar di Kabupaten Kayong Utara. Hasil kesimpulan tersebut berupa persentase kondisi sanitasi di setiap Kecamatan yang merupakan area bersiko sanitasi sangat tinggi dan dapat mengetahui permasalahan yang mendesak serta dapat merumuskan rekomendasi terhadap masalah tersebut. Selain itu hasil dari penelitian ini juga merumusakan kegiatan-kegiatan quick win yang dapat dilakukan oleh Pemerintah Kabupaten Kayong Utara.

\section{Metodologi Penelitian}

Adapun metodologi yang dilakukan pada penelitian ini dapat lebih rinci dilihat pada bagan alir Gambar 1.

\subsection{Metode kajian sanitasi sekolah}

a. Identifikasi masalah dan survey awal

Penelitian ini dimulai dengan mengidentifikasi masalah kemudian studi literatur dan mengumpulkan data-data terkait antara lain data

Tabel.1 Nama desa yang berkategori resiko sangat tinggi

\begin{tabular}{|c|c|c|}
\hline No & Nama Desa & Kategori Resiko Sanitasi \\
\hline 1 & Pangkalan Buton & Resiko Sangat Tinggi \\
\hline 2 & Pampang Harapan & Resiko Sangat Tinggi \\
\hline 3 & Benawai Agung & Resiko Sangat Tinggi \\
\hline 4 & Gunung Sembilan & Resiko Sangat Tinggi \\
\hline 5 & Nipah Kuning & Resiko Sangat Tinggi \\
\hline 6 & Pemangkat & Resiko Sangat Tinggi \\
\hline 7 & Padu Banjar & Resiko Sangat Tinggi \\
\hline 8 & Perjalanan & Resiko Sangat Tinggi \\
\hline 9 & Batu Barat & Resiko Sangat Tinggi \\
\hline 10 & Rantau Panjang & Resiko Sangat Tinggi \\
\hline 11 & Matan Jaya & Resiko Sangat Tinggi \\
\hline 12 & Teluk Batang & Resiko Sangat Tinggi \\
\hline 13 & Sungai Paduan & Resiko Sangat Tinggi \\
\hline 14 & Banyu Abang & Resiko Sangat Tinggi \\
\hline 15 & Teluk Batang Utara & Resiko Sangat Tinggi \\
\hline 16 & Telaga Arum & Resiko Sangat Tinggi \\
\hline 17 & Wonorejo & Resiko Sangat Tinggi \\
\hline 18 & Podo Rukun & Resiko Sangat Tinggi \\
\hline
\end{tabular}

Sumber: Studi EHRA (2018) 


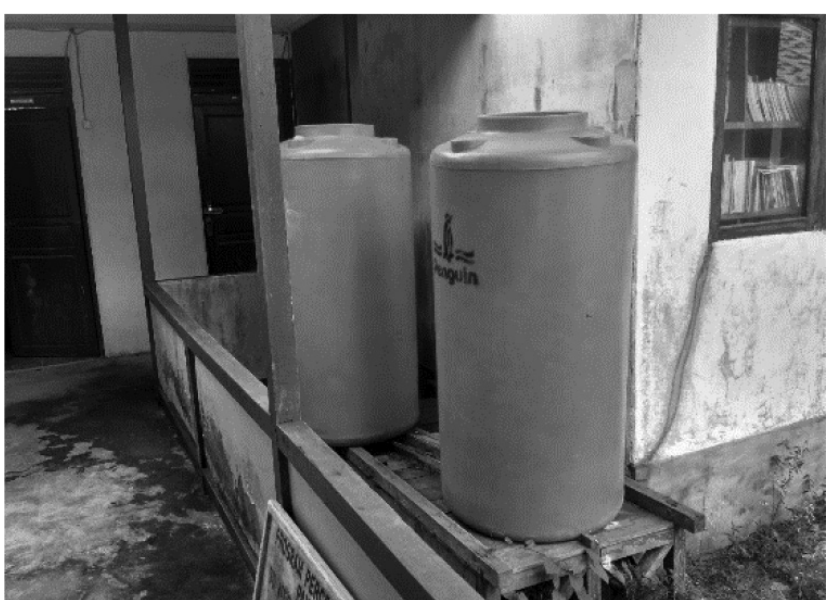

Gambar 2. Tandon Air Hujan di SD Negeri 04 Desa Pangkalan Buton

Hasil survei (2018)

sekunder dari instansi terkait dan data primer berupa data yang pada saat survey. Pada tahap awal penelitian ini dilakukan identifikasi masalah berdasarkan data sekunder berupa area berisiko sanitasi dan data survey awal terkait dengan sanitasi sekolah.

b. Tinjauan pustaka

Tinjauan pustaka dilakukan dengan cara mengumpulkan pustaka-pustaka yang berkaitan dengan hasil dari identifikasi masalah yang telah dilakukan. Sehingga teori-teori dari pustaka tersebut dapat mendukung dalam penelitian.

c. Pengumpulan data primer

Pengumpulan data primer dilakukan dengan beberapa cara antara lain:

1. Observasi lapangan

Observasi lapangan dilakukan untuk mengetahui kondisi yang sebenarnya terkait dengan sanitasi sekolah.

2. Self assesment

Penyebaran formulir self assesment yang diisi oleh pihak sekolah dasar. Pemilihan sekolah dasar yang dilakukan observasi lapangan dan pengisian formulir self assement mengacu kepada sekolah dasar yang berada dalam kategori beresiko sangat tinggi yaitu 33 sekolah dasar dari 18 desa di Kabupaten Kayong Utara.

\subsection{Langkah-langkah dalam kajian sanitasi} sekolah

Ada tiga langkah yang harus dilaksanakan, terutama menyangkut pengumpulan data dan konsultasi dengan Pokja menyangkut penjelasan area berisiko. Pertama, menampilkan peta area berisiko untuk komponen air limbah domestik dan persampahan. Kedua, memetakan kondisi sanitasi sekolah. Ketiga, mengidentikasi masalah mendesak
1. Memahami Area Berisiko

Dinas Dikbud hanya perlu menyalin peta area berisiko yang ada di Buku Putih atau SSK (pemutakhiran) untuk mengetahui tingkat risiko sanitasi di tiap-tiap desa/kelurahan. Peta ini didapatkan dari pengolahan data sekunder, pengamatan lapangan, diskusi antar-stakeholder (persepsi SKPD), dan hasil survey Environmental Health Risk Assessment (EHRA) pada saat menyusun Buku Putih. Tiap kelurahan mempunyai tingkat risiko berbeda-beda, mulai dari risiko rendah hingga risiko sangat tinggi. Dengan memahami area berisiko, Dinas Dikbud nantinya akan banyak terbantu ketika memetakan kondisi sanitasi sekolah-sekolah: apakah suatu SD/MI beada di wilayah berisiko tinggi atau rendah.

2. Memetakan Kondisi Sanitasi Sekolah

Langkah berikutnya adalah memetakan kondisi sanitasi sekolah saat ini. Hal ini dilakukan untuk seluruh sekolah SD/MI negeri dan swasta di kabupaten/kota. Dinas Dikbud dapat mengerahkan seluruh SD di kabupaten/kota untuk melakukan pemutakhiran data dengan mengisi lembarlembar pertanyaan (kuesioner). Dinas Dikbud dapat memandu sekolah agar mengisi kuesioner tersebut dengan teliti dan seakurat mungkin. Mengingat sekolah lokusnya sempit dan jelas dan tidak sekompleks permasalahan sanitasi di wilayah permukiman, maka proses pengumpulan data dan pemetaannya pun diharapkan akan lebih sederhana.

a. Profil sekolah

Kumpulkan dan manfaatkan data profil sekolah yang ada di Dinas (Dapodik) dan kelompokkan berdasarkan kelurahan. Pastikan datanya memuat sekurang-kurangnya: Nama sekolah,

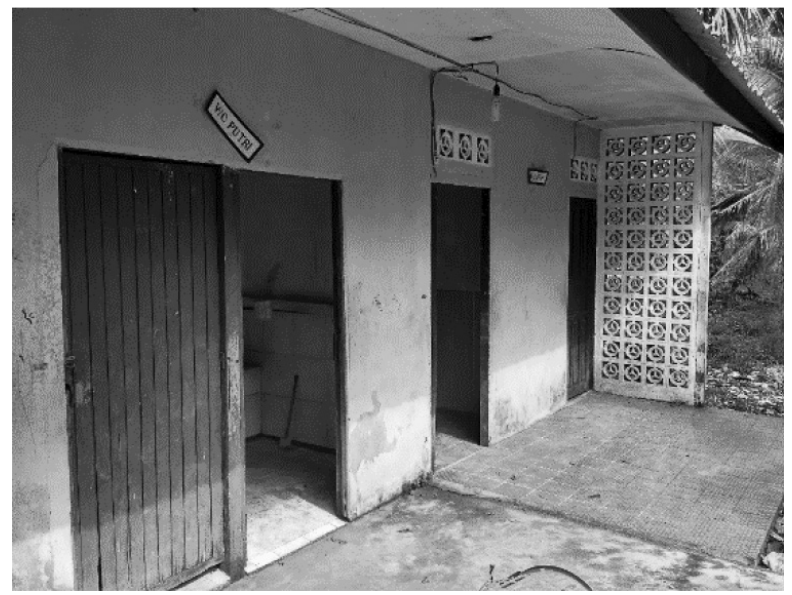

Gambar 3. Toilet Terpisah Siswa Putri dan Putra SD Negeri 05 Sungai Paduan Kecamatan Teluk Batang Hasil survei (2018) 


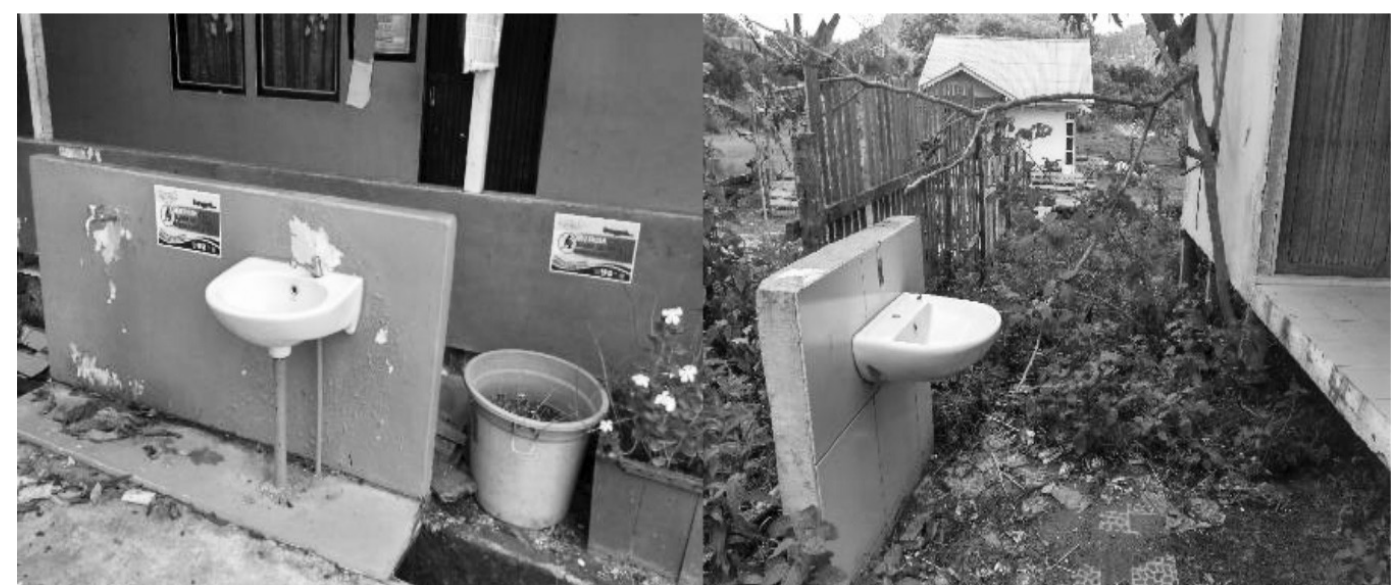

Gambar 4. Fasilitas Cuci Tangan di SD Negeri 04 Kalimas Kecamatan Teluk Batang dan SD Negeri 16 Tambak Rawang Desa Gunung Sembilan Kecamatan Sukadana

Hasil survei (2018)

Jumlah Kelas, Jumlah Guru (L/P), Jumlah siswa (L/P). Data ini biasanya tersedia dengan mendetail di Dinas Pendidikan, sehingga tinggal mengkonsolidasikan saja. Tuangkan dalam bentuk tabel.

b. Profil komponen sanitasi sekolah

Lengkapi dengan data berikut: data air minum, toilet guru dan siswa, septic tank/IPAL, tempat sampah, TPS, saluran air, fasilitas cuci tangan dan berwudhu. Perhatikan juga apakah toilet yang tersedia juga memiliki fasilitas yang mendukung pengelolaan menstruasi, seperti: cermin, gantungan, dan tempat sampah (menstrual).

c. Self-assessment oleh sekolah.

Penilaian kondisi tiap-tiap komponen sanitasi dilakukan oleh setiap sekolah secara bottom up melalui penilaian mandiri (self-assessment) dengan menggunakan kriteria yang disiapkan.

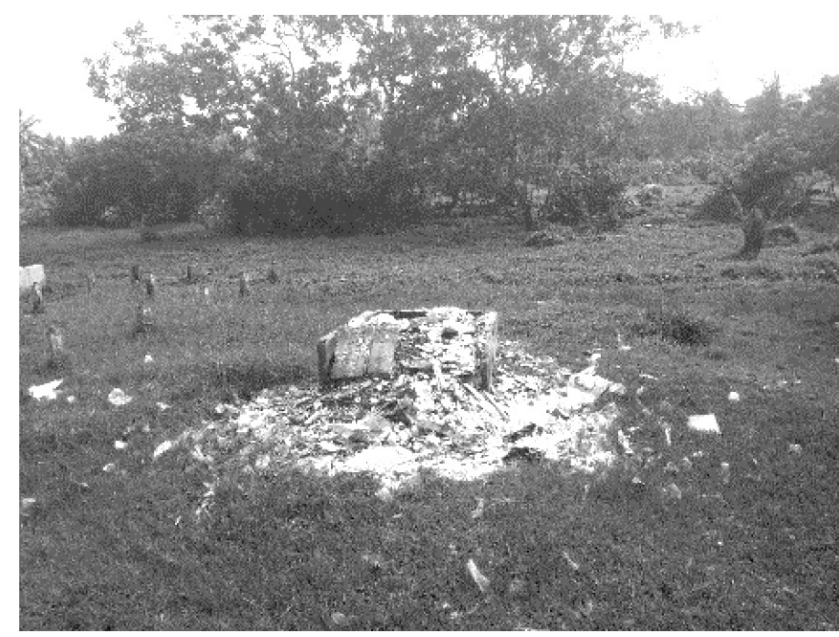

Gambar 5. Tempat Pembakaran Sampah di SD Negeri 05 Rantau Panjang Kecamatan Simpang Hilir Hasil survei (2018)
Penilaian mandiri dapat menggunakan spread sheet tools sederhana dan sekolah hanya memberi tanda "centang" untuk memberikan penilaian.

3. Pemetaan sanitasi sekolah.

Selanjutnya konsolidasikan data dari tiap-tiap sekolah dan kelompokkan dalam kelurahan. Susun tabel konsolidasi berikut untuk menggambarkan kondisi riel (pemetaan) sanitasi sekolah di seluruh wilayah kabupaten/kota berdasarkan komponen. Pemerintah daerah, khususnya Dinas Pendidikan dan Kebudayaan, harus memberi perhatian pada komponen-komponen sanitasi yang nilainya buruk atau sedang.

\section{Hasil Dan Pembahasan}

Kajian sanitasi sekolah Kabupaten Kayong Utara mengacu Area Berisiko Sanitasi yang telah ditetapkan pada studi EHRA. Survey lapangan kajian ini ke sekolah - sekolah yang termasuk di desa berisiko sanitasi tinggi. Adapun dalam studi EHRA pengklasifikasian kategori resiko dibagi menjadi 3 yaitu Tidak Berisiko, Resiko Sedang dan Resiko Sangan Tinggi. Namun pada kajian sanitasi sekolah di Kabupaten Kayong Utara ini akan melakukan kajian berdasarkan acuan dari studi EHRA dalam kategori berisiko sangat tinggi. Ruang lingkup wilayah pengumpulan data dan kajian yaitu pada area-area berisiko sanitasi yang sangat tinggi. Dari hasil studi EHRA ini desa - desa yang termasuk area berisko sangat tinggi berjumlah 18 desa di 4 Kecamatan (selain Kecamatan Karimata dan Kecamatan Pulau Maya) yaitu di kecamatan Sukadana, Kecamatan Teluk Batang, Kecamatan Simpang Hilir dan Kecamatan Seponti. Desa - desa tersebut antara lain dapaty dilihat pada Tabel 1 . 
Tabel 2. Penilaian Form Self-Assesment Kabupaten Kayong Utara

\begin{tabular}{lcl}
\hline \multicolumn{1}{c}{ Kabupaten Kayong Utara } & $\begin{array}{c}\text { Kondisi Sanitasi } \\
(\%)\end{array}$ & Nilai \\
\hline Toilet Guru & 60.52 & Cukup \\
Toilet Siswa & 59.12 & Cukup \\
Sumber Air & 80.12 & Baik \\
Fasilitas Cuci Tangan & 35.52 & Buruk \\
Tempat Penampungan Sampah (TPS) & 45.44 & Buruk \\
Saluran Air (Drainase) & 43.42 & Buruk \\
Pendidikan dan Praktek PHBS & 47.32 & Buruk \\
\hline
\end{tabular}

Berdasarkan data hasil identifikasi prasarana sanitasi sekolah di setiap desa yang dilakukan secara langsung, dapat diketahui antara lain:

\subsection{Sumber Air Bersih}

Sumber air bersih yang paling dominan yang digunakan sekolah yaitu air hujan yaitu sebanyak 22 sekolah menggunakan air hujan sebagai sumber air bersih selain menggunakan air hujan ada bebera sekolah juga menggunakan air perpipaan dalam hal ini berupa perpipaan dari mata air gunung dengan sistem gravitasi ataupun menggunakan air dari PDAM.

\subsection{Toilet}

Berdasarkan data yang diperoleh disetiap sekolah sudah dipisahkan antara siswa laki - laki ataupun perempuan, namun masih banyak juga toilet yang tidak terpisah yaitu toilet campur. Kondisi Toilet Tidak Terpisah sering ditemui kondisi yang kotor ataupun rusak.

\subsection{Fasilitas Cuci Tangan}

Fasilitas cuci tangan sangat jarang dimilki oleh sekolah namun ada beberapa sekolah yang miliki fasilitas cuci tangan. Beberapa ditemukan fasilitas cuci tangan dalam keadaan rusak. Hal ini terjadi dikarena belum ada kesadaran dari siswa dalam perilaku hidup bersih dan sehat (PHBS) sehingga kurang menjaga fasilitas tersebut.

\subsection{Tempat Penampungan Sementara (TPS)}

Pelayanan persampahan yang dilakukan oleh dinas Pekerjaan Umum Kabupaten Kayong Utara hanya di sekitar Kecamatan Sukadana. Oleh karena itu pengelolaan sampah di kecamatan lainnya tidak ada, warga membuang sampah ditanah kosong kemudian ditimbun atau tidak ditimbun namun mayoritas masyarakat kecamatan tersebut membakar sampah yang mereka hasilkan. Oleh karena itu berdasarkan data kuisioner dan survey lapangan tidak menemukan Tempat Penampungan Sementara (TPS).

\subsection{Saluran Air/Drainase}

Saluran Air/ Drainase sangat minim dimiliki oleh sekolah, beberapa sekolah ditemukan drainase digunakan untuk limpasan air hujan namun berdasarkan data sangat sedikit sekolah yang memiliki saluran drainase sehingga ketika air limpasan hujan tidak dapat ditangani maka akan terjadi genangan genangan air disekitar sekolah.

Berdasarkan hasil penyebaran form SelfAssesment yang telah dilakukan analisis, kondisi sanitasi sekolah dasar di Kabupaten Kayong Utara dapat dilihat pada Tabel 2.

\section{Hasil dan Pembahasan}

Pembahasan pada setiap indikator diuraikan sebagai berikut:

\subsection{Toilet guru}

Penialaian self- assessment dari pihak sekolah bahwa kondisi prasaran sanitasi berupa toilet guru dalam keadaan cukup baik. Toilet guru sudah dipisah dengan toilet siswa, namun toilet guru belum dipisah antara toilet guru laki-laki dan toilet guru perempuan. Kondisi kebersihan toilet tersebut juga bervariasi pada penilaian tersebut.

\subsection{Toilet siswa}

Toilet siswa pada hasil penilaian sudah cukup baik, penilaian toilet siswa ini antara lain:

- Apakah toilet siswa dipisah atau tidak terpisah (TT)

- Apakah jumlah toilet mencukup dibandingkan dengan jumlah siswa dengan perbandingan 1:50

- Apakah toilet tersebut selalu bersih

- Apakah memiliki saluran pem buangan berupa tangki septik

Dalam hal ini perlu diperhatikan terkait kebersihan 
toilet dan saluran pembuangan dari toilet tersebut. Saluran pembuangan tinja idealnya berupa tangki septik yang memiliki periode waktu pengurasan, namun pada hasil survey lapangan tangki septik yang digunakan tidak pernah disedot oleh sebab itu potensi pencemaran tanah dan air tanah sangat besar karena yang digunakan sebagai saluran pembuangan tinja bukan tangki septik sesuai standar namun berupa cubluk.

\subsection{Sumber air}

Sumber air yang digunakan oleh sekolah mayoritas menggunakan air hujan dan air perpipaan. Berdasarkan hasil self-assessment tersebut kualitas air yang digunakan bagus dan layak digunakan.

\subsection{Fasilitas cuci tangan}

Penialaian Fasilitas Cuci Tangan untuk Kabupaten Kayong Utara mendapat nilai buruk. Berdasarkan self-assesment bahwa fasilitas pencuci tangan tidak banyak dimiliki oleh sekolah, jika ada sekolah yang memiliki fasilitas tersebut, jumlah yang tersedia tidak sesuai dengan form self-assessment. Pada form self-assesement tercantum bahwa fasilitas pencuci tangan sesuai jumlah kelas/lebih. Kemudian fasilitas pendukung dari tempat cuci tangan ini seperti sabun mayoritas tidak tersedia.

\subsection{Tempat Penampungan Sementara (TPS)}

Penilaian terkait dengan Tempat Penampungan Sementara (TPS) untuk Kabupaten Kayong Utara mendapat nilai buruk. Salah satu penyebabnya adalah layanan pengangkutan sampah oleh dinas PU Kabupaten Kayong Utara saat ini hanya melayani ibu kota kabupaten yaitu Kecamatan Sukadana. Penilaian lainnya yang termasuk indikator ini yaitu terkait dengan jumlah tempat sampah di sekolah, sampah dibersihkan setiap hari dan kebersihan ruang kelas. Berdasarkan hasil wawancara di beberapa sekolah di area kajian dan berdasarkan form self-assessment kebersihan ruang kelas dalam kondisi bersih dikarenakan dibersihkan setiap hari, namun sampah di sekolah tidak ada layanan pengangkutan sehingga mayoritas sekolah di Kabupaten Kayong Utara membakar sampah untuk penanganan sampah tersebut.

\subsection{Saluran Air (Drainase)}

Saluran air atau drainase sangat minim dimiliki oleh sekolah di area kajian di Kabupaten Kayong Utara, beberapa sekolah ditemukan drainase digunakan untuk limpasan air hujan namun berdasarkan data sangat sedikit sekolah yang memiliki saluran drainase sehingga ketika air limpasan hujan tidak dapat ditangani maka akan terjadi genangan - genangan air disekitar sekolah.

\section{Identifikasi Permasalahan Mendesak}

Berdasarkan hasil survey dan self-assesment yang dilakukan oleh pihak sekolah serta diskusi pada sekolah yang kondisi sanitasinya buruk dengan tingkat kepadatan penduduk yang tinggi dan pantas untuk dijadikan area prioritas sanitasi pemukiman, maka permasalahan yang mendesak yaitu

\subsection{Tingkat Pemahaman PHBS yang masih rendah yang dimiliki murid dan guru di sekolah.}

Tingkat pemahaman PHBS yang masih rendah merupakan salah satu faktor penting dalam solusi penyelesaian sanitasi sekolah. Jika pemahaman PHBS tinggi maka pihak sekolah dan juga murid akan menjaga fasilitas-fasilitas sanitasi yang dibangun, hal tersebut akan menambah usia pakai dari fasilitas sanitasi atau dengan kata lain bahwa pihak sekolah dan muridlah yang menjaga dan merawat fasilitas tersebut.

\subsection{Fasilitas Pencuci Tangan yang sebagian besar sekolah dasar tidak memadai}

Sebagian besar sekolah tidak memiliki fasilitas cuci tangan, jika ada fasilitas cuci tangan tidak memadai. Contoh fasilitas tersebut dapat dilihat pada

\section{Gambar 4.}

\subsection{Saluran Air yang rusak}

Berdasarkan hasil self-assessment dan observasi ke lapangan bahwa saluran air di sekolah-sekolah banyak yang tidak berfungsi atau dalam keadaan rusak, tidak jarang ditemui bahwa di halaman sekolah terjadi genangan air bekas limpasan air hujan yang tidak dikelola dengan baik oleh pihak sekolah. Hal ini merupakan permasalahan yang mendesak, mengingat bahwa genangan-genangan air dapat berpotensi menjadi media berkembangnya vektor-vektor penyakit.

\subsection{Tidak adanya TPS Sekolah}

Tidak adanya TPS sekolah sehingga pihak sekolah membakar sampah lahan kosong sehingga berpotensi pencemaran udara.

\section{Kesimpulan}

1. Pada saat ini kondisi sanitasi sekolah dasar Kabupaten Kayong Utara yang dinilai dari beberapa aspek sanitasi termasuk dalam kategori buruk.

2. Perlu dilakukan tindakan aksi untuk mengatasi permasalahan yang mendesak antara lain terkait dengan tingkat pemahaman siswa 
terkait perilaku hidup bersih dan sehat, fasilitas cuci tangan, saluran drainase serta pengelolaan persampahan di sekolah. Selain itu, perlu adanya peran dari dinas terkait dalam mengatasi permasalahan yang mendesak tersebut agar kondisi sanitasi sekolah dasar di Kabupaten Kayong dapat menjadi lebih baik.

\section{Daftar Pustaka}

Ana, G, Oloruntoba, E, Stridhar, M, \& Adekolu, A, 2008. Water and Sanitation problems in selected schools in Ibadan, In: Proceedings of the 33rd WEDC International Conference, Nigeria.

Adams, J, Bartram, J, Chartier, Y \& Sims, 2009. Water, sanitation and hygiene standards for schools in low-cost settings, Geneva.

Basilius K. Cahyanto. 2008. Sanitasi Total Berbasis Masyarakat. Aceh: Aceh Media Grafika.

Boschi-Pinto, C, Velebit, L, \& Shibuya, K, 2008. Estimating child mortality due to diarrhoea in developing countries, Bulletin of the World Health Organization.

Burgers, L, 2000, Background and rationale for school sanitation and hygiene education, New York.

Dina Andriani, et. al., 2013. Studi tentang Sanitasi Lingkungan SD Negeri di Kecamatan Sungai Beremas Kabupaten Pasaman Barat. Jurnal. Sumatera Barat: Geografi STKIP PGRI.

Freeman, dkk., 2014. Systematic Review: Hygiene and health: Systematic review of handwashing practices worldwide and update of health effects, Tropical Medicine and International Health, Vol 19 No. 8 p906-916.

Kementerian Agama Republik Indonesia. 2012. Pedoman Teknis Pengelolaan Kebersihan Lingkungan Madrasah. Jakarta.

Laporan Studi EHRA, 2018. Kelompok Kerja Air Minum dan Sanitasi, Kabupaten Kayong Utara

Mooijman, A, 2012. Water, Sanitation and Hygiene (WASH) in Schools: A Companion to the Child Friendly Schools Manual, UNICEF.

O'Reily et. al. 2006. The impact of a school-based safe water and hygiene programme on knowledge and practices of students and their parents. Nyanza Province, Western Kenya. Epidemiology and Infection, 136(1), pp. 80-91.

Peraturan Menteri Pendidikan Nasional Nomor 24 Tahun 2007 Standar Sarana dan Prasarana Sekolah Dasar/Madrasah Ibtidaiyah, Sekolah Menegah Pertama/Madrasah Tsanawiyah dan Sekolah Menengah Atas/Madrasah Aliyah. Jakarta.
Peraturan Menteri Kesehatan Nomor 3 tahun 2014 Sanitasi Total Berbasis Masyarakat. Jakarta.

Pusat Data \& Statistik Pendidikan dan Kebudayaan, 2017. Profil Sanitasi Sekolah 2017. Jakarta.

Purba,2010.Pedomanumumsanitasidanhigienesekolah: Program Penyediaan Sarana Air Minum dan Sanitasi Berbasis Masyarakat (Pamsimas) Komponen B. Bappenas, Kemen PU, Kemenkes, Kemendagri, Kemenkeu \& The World Bank. Jakarta.

Soemirat, S. 2002. Kesehatan Lingkungan. Gajah Mada University Press. Yogyakarta. 